\title{
Práticas de gestão de pessoas: uma análise das melhores cooperativas para trabalhar
}

\author{
People management practices: an analysis of the best cooperatives to work
}

\begin{abstract}
Resumo
O presente estudo teve o objetivo de identificar as principais práticas de gestão de pessoas adotadas pelas melhores cooperativas para trabalhar, segundo um ranking da Revista Você S/A de 2017. No intuito de atender ao objetivo, realizou-se um estudo de caráter descritivo e abordagem qualitativa e quantitativa. A coleta dos dados ocorreu a partir de análise documental, através da consulta do guia da Revista Você S/A com as Melhores Empresas para Trabalhar de 2017, além de acesso ao site e aos relatórios de sustentabilidade e gestão do ano de 2017 das cooperativas. Percebe-se que as 16 cooperativas premiadas pertencem a dois ramos, crédito e saúde e possuem práticas de gestão de pessoas consolidadas. No setor de crédito, obteve-se maior expressividade das práticas de gestão de pessoas de endomarketing e treinamento e desenvolvimento (T\&D). Enquanto no setor de saúde, as práticas mais significativas foram, benefícios sociais e T\&D.
\end{abstract}

Palavras-chave: cooperativas, cooperativas de crédito, cooperativas de saúde, práticas de gestão de pessoas.

\begin{abstract}
The present study had the objective of identifying the main practices of people management adopted by the best cooperatives to work, according to a ranking of the magazine Você S/A of 2017. In order to meet the objective, a descriptive and qualitative and quantitative research was carried out. The data collection was based on documentary analysis, through the consultation of the magazine Você S/A with the Best Companies to Work in 2017, as well as access to the website and the sustainability and management reports for the year 2017 of the cooperatives. It can be noticed that the 16 cooperatives awarded belong to two branches, credit and health. With regard to people management practices, the two cooperatives have established practices. In the credit sector, there was greater expressiveness in endomarketing and training and development. While in the health sector, the most significant factors were, social benefits and T\&D.
\end{abstract}

Keywords: cooperatives, credit cooperatives, health cooperatives, people management practices.

Amanda Oliveira Ramadam ${ }^{\text {I }}$, Henrique de Lima Melo França ${ }^{\text {II }}$, Laurine Bressa ${ }^{\text {III }}$, Tarízi Cioccari Gomes ${ }^{\text {IV }}$, Vania de Fátima Barros Estivalete ${ }^{\mathrm{V}}$.

${ }^{\text {I }}$ Universidade Federal de Santa Maria - UFSM, Santa Maria, RS. amandaramadam@gmail.com

${ }^{\text {II } U n i v e r s i d a d e ~ F e d e r a l ~ d e ~ S a n t a ~ M a r i a ~-~ U F S M, ~ S a n t a ~ M a r i a, ~ R S . ~ h e n r i q u e . d l m . f r a n c a @ g m a i l . c o m ~}$

${ }^{\text {III }}$ Universidade Federal de Santa Maria - UFSM, Santa Maria, RS. bressa.laurine@gmail.com

IV Universidade Federal de Santa Maria - UFSM, Santa Maria, RS. tarizi@hotmail.com

v Universidade Federal de Santa Maria - UFSM, Santa Maria, RS. vaniaestivalete@ufsm.br 


\section{Introdução}

O trabalho é parte essencial na vida do homem, já que constitui o aspecto da vida que lhe dá estatuto e o liga à sociedade (LACOMBE, 2011). Desta forma, a complexidade do contexto organizacional, o aumento nas demandas, os ambientes de produção inovadores e a competitividade fizeram com que os colaboradores fossem mais valorizados nas organizações, desenvolvendo por parte das empresas, uma maior preocupação com a melhoria das condições para maximizar o desempenho e a satisfação no trabalho (DELFINO; LAND; RUFINO, 2010).

As cooperativas são instituições que possuem algumas singularidades e têm na sua concepção a finalidade de prestar serviços de qualidade aos seus associados. Para Zucatto e Silva (2017), o elemento que distingue a organização cooperativa de outras organizações do mesmo formato, envolve os indivíduos, nas cooperativas as pessoas têm como objetivo central satisfazerem objetivos comuns, sendo esta uma das principais diferenças com as empresas de capital, cujo objetivo principal é o retorno para o investidor. As cooperativas surgem por meio da união de diversos indivíduos que possuem interesse em comum, os quais buscam, desse modo, o desenvolvimento do ambiente onde vivem (COMUNELLO et al., 2014).

Nesse sentido, as cooperativas possuem características que, aparentemente, possibilitam as suas estruturas a harmonia e a democratização, de forma transparente (SIMIONI et al., 2009). Segundo Guardabassio, Amorim e Pereira (2013), a concepção do cooperativismo está vinculada à valorização da prosperidade conjunta e não apenas em nível pessoal. Sendo assim, o cooperativismo preconiza uma sociedade mais equitativa, democrática e sustentável (VEIGA; FONSECA, 2001).

Diante desse contexto, o cooperativismo é constituído por um conjunto de pessoas que visam o bem comum apresentando alternativas vantajosas a todos os envolvidos (CARVALHO; SILVA, 2017). Uma vez que, a base desse sistema econômico é a cooperação, se bem integrada ao conjunto de políticas e práticas que a formam, a gestão atende aos interesses e expectativas tanto da empresa quanto das pessoas (DUTRA, 2009).

Dessa forma, as cooperativas acabam sendo influenciadas fortemente pela questão política do ambiente em que estão inseridas. Tal ambiente que, por seu turno, constitui uma forte associação entre o cooperado e a cooperativa. Nesse contexto, são construídas as conexões de lealdade, visto que as cooperativas passam a compartilhar os interesses e a oferecer possibilidades de apoio mútuo (SIMIONI et al., 2009).

As organizações cooperativas foram originalmente utilizadas para obter, de forma compartilhada, a satisfação de uma necessidade comum, tornando-se uma alternativa às possibilidades ou à falta de possibilidades (CHARTERINA, 2014). Assim, o elemento que diferencia a cooperativa de outras organizações do mesmo formato provém da expectativa dos sócios, os quais, nestas organizações, trazem o capital para que a cooperativa assegure sua negociação (FLAVIANO, 2014).

Nessa perspectiva, percebe-se uma forte relação entre as características do cooperativismo e o propósito da área de gestão, especialmente a gestão de pessoas, no sentido em que, ambas buscam a colaboração e o alcance de um objetivo comum, impactando nas ações dos colaboradores diante das situações. Segundo Carvalho e Peres (2015), a gestão de pessoas é formada pelos elementos que, de modo direto ou indireto, influenciam no comportamento das pessoas nos contextos organizacionais. Para os autores, a gestão de pessoas representa um elemento estratégico nas organizações, sendo inserida em todas as áreas de negócios, dado que o potencial de mudanças e de informatização dos procedimentos de gestão, de modo geral, estão sendo conhecidos.

De acordo com Demo (2010), as políticas de gestão de pessoas têm assumido um sentido especial ao desenvolver, valorizar e reter talentos nas organizações. Para este autor, a área é responsável pelo bem-estar e realização dos indivíduos na organização, visto que esta área entende o colaborador como elemento fundamental para o alcance de metas e maior competitividade 
organizacional. Para Ribeiro et al. (2015), as práticas de gestão de pessoas tornaram-se essenciais para que houvesse a melhoria do desempenho organizacional. Sendo assim, essas práticas podem assumir um papel importante no processo de desenvolvimento dos colaboradores no ambiente laboral, visto que indicam os cuidados e investimentos que a organização deve ter com o seu colaborador (MARIANO; MOSCON, 2018).

Inserido neste contexto, este artigo originou-se do seguinte questionamento: quais as práticas de gestão de pessoas adotadas pelas cooperativas de crédito e saúde consideradas melhores para se trabalhar, de acordo com o ranking da Revista Você S/A de 2017? Nesse sentido, o presente estudo teve como objetivo identificar as principais práticas de gestão de pessoas adotadas pelas melhores cooperativas para trabalhar, segundo um ranking da Revista Você S/A de 2017.

A escolha da temática de estudo justifica-se por considerar relevante reforçar as práticas de gestão de pessoas praticadas pelas cooperativas que se destacam no ranking da Revista Você S/A de 2017. Segundo Rossés et al. (2019), a gestão de pessoas ocupa papel central nas organizações, uma vez que, a principal vantagem competitiva de qualquer organização são os indivíduos que nela atuam. Além disso, estes autores destacam que ainda são escassos os estudos envolvendo a temática de gestão de pessoas nas organizações cooperativas. Corroborando, Demo, Fogaça e Costa (2018) afirmam a necessidade de estudos sobre a temática de práticas de gestão de pessoas, visto que esta área possui um caráter estratégico nas organizações.

No desenvolvimento deste artigo apresenta-se o referencial teórico com os principais conceitos que envolvem o tema de cooperativas e gestão de pessoas. Em seguida, apresenta-se a metodologia de pesquisa utilizada. Na sequência, apresentam-se os resultados, seguidos de suas análises e por fim, as considerações finais, apontando as limitações e direcionamentos para novas pesquisas.

\section{Referencial Teórico}

Nessa seção serão apresentadas as temáticas que sustentam o estudo para melhor compreender o tema abordado. Essa base teórica subdivide-se nos temas: cooperativismo e gestão de pessoas.

\subsection{Cooperativismo}

O cooperativismo preocupa-se com a coletividade, valorização dos indivíduos e a sua união, em prol de um objetivo comum, assim as organizações cooperativas estão pautadas em transformar os desafios da sociedade em oportunidades (TARADENKO, 2016). Nessa perspectiva, volta-se ao entendimento de Comunello et al. (2014), ao comentarem que o cooperativismo age a partir de um modelo mais justo, contribuindo para a convivência balanceada entre o fator econômico e o social, em que beneficia todos os membros a uma certa cooperativa com uma distribuição equitativa dos saldos em um intervalo de tempo.

No Brasil, a representação nacional do cooperativismo ocorre por meio da Organização das Cooperativas Brasileiras (OCB), criada em 1969, com o intuito de atuar em prol do movimento cooperativista, sendo responsável pela promoção, fomento e defesa do sistema cooperativista, em todas as instâncias políticas e institucionais, reconhecida como representante oficial do setor no Brasil (GUARDABASSIO; AMORIM; PEREIRA, 2013). Logo, em âmbito nacional, a representação do cooperativismo ocorre por meio da $\mathrm{OCB}$ e estadual, por meio da Organização das Cooperativas Estaduais (OCE) (VEIGA; FONSECA, 2001).

Para Comunello et al. (2014), surgiram ao longo dos dois últimos séculos, incontáveis cooperativas em praticamente todos os países. No entanto, cada cooperativa possui um formato específico e um foco diferente, em diversos contextos, desde voltadas ao consumo, em que 
organizações pertencem aos cooperados, capazes de comercializarem bens/ serviços por preços mais corretos e de melhor qualidade (COMUNELLO et al., 2014).

Nesse sentido, de acordo com dados da Organização das Cooperativas Brasileiras (OCB, 2018), o cooperativismo pode ser visto como uma filosofia de vida, com o intuito de transformar o mundo em um lugar melhor para todos. Atualmente, o cooperativismo apresenta números expressivos em relação a economia mundial, visto que proporciona 250 milhões de empregos em mais de 100 países (OCB, 2018). Entretanto, sua história passou a ganhar força desde o século XIX, pela ação de pequenos grupos de trabalhadores que se organizam em cooperativas na Europa (VEIGA; FONSECA, 2001).

De acordo com Taradenko (2016), a primeira cooperativa que se organizou de maneira "ideal" foi chamada Pioneiros de Rochdale, em Manchester, na Inglaterra, em 1844. Desde sua concepção a cooperativa estabeleceu um programa contendo princípios e regras de organização e de funcionamento das cooperativas (TARADENKO, 2016). Os tecelóes estavam com dificuldades financeiras para comprar gêneros de primeira necessidade e viram no cooperativismo uma alternativa, para realizar compras desses produtos de forma conjunta, conseguindo, assim, melhor preço (VEIGA; FONSECA, 2001). Contudo, ressalta-se que, os trabalhos de forma cooperada em sua essência, existem desde os Astecas e Incas (na agricultura), babilônios e palestinos (PILETTI; BORGES; BARROS, 2015).

No Brasil, o cooperativismo surgiu como uma forma de organização, inicialmente em Minas Gerais, em 1889, com a Fundação da Cooperativa Econômica dos Funcionários Públicos de Ouro Preto, que tinha como foco principal o consumo de produtos agrícolas (OCB, 2018). Segundo Almeida (2008), as cooperativas estão enquadradas no terceiro setor, assim constituem uma alternativa diante das organizações tradicionais, mesmo que se apresente como uma organização complexa, já que pode possuir diferentes propósitos. O cooperativismo pressupõe uma sociedade mais equitativa, democrática e sustentável (VEIGA; FONSECA, 2001).

As cooperativas são instituições que possuem algumas singularidades, entre elas, seu arranjo institucional, o qual se baseia em princípios doutrinários (DUARTE; JESUS-LOPES; SANTOS, 2016). No que tange aos princípios, o sistema cooperativista, possui sete princípios que funcionam como linhas orientadoras pelas quais as cooperativas efetivam a prática os seus valores, são eles: adesão voluntária e livre; gestão democrática; participação econômica dos membros; autonomia e independência; educação, formação e informação; intercooperação; e interesse pela comunidade (OCB, 2018).

Diante deste contexto, Almeida (2008) ressalta que devido ao seu caráter universal, o cooperativismo presume o desenvolvimento independente da cidade, estado ou país em que está inserido. As origens deste sistema estão associadas a valores universais, língua, credo ou nacionalidade, tornando a sociedade mais justa e fraterna (ALMEIDA, 2008).

Em conformidade com o exposto, Simioni et al. (2009) comenta que as especificidades das cooperativas permitem a suposição de que elas ocupam um espaço diferenciado no mercado, a partir do momento em que os seus valores forem incorporados em uma postura ética mais incrementada, com base nos preceitos fundamentais.

Sendo assim, percebe-se que as preocupações do sistema cooperativo vão além das questões econômicas, este sistema preocupa-se também com aspectos sociais e ambientais dos contextos em que estão inseridos. Segundo Rossés et al. (2019), os colaboradores buscam nas cooperativas, opções que satisfaçam a necessidade de emprego e renda. Diante do exposto, torna-se necessário compreender como a área de gestão pessoas pode contribuir para o desenvolvimento dos indivíduos no sistema cooperativista. 


\subsection{Gestão de Pessoas}

$\mathrm{Na}$ atualidade, as demandas do mundo do trabalho têm exigido cada vez mais dos colaboradores, desta forma as políticas e práticas de gestão de pessoas, estão detendo maior atenção das organizações e tornaram-se especialmente importantes quando se consideram as demandas impostas aos colaboradores (COSTA; DEMO; PASCHOAL, 2019). Assim, a área de Gestão de pessoas tem se tornado cada vez mais relevante, uma vez que a maior parte do tempo das vidas das pessoas é passado dentro das empresas em que atuam (VERGARA, 2016).

Desse modo, com as mudanças ocorridas na década de 90 nas organizações, os gestores passaram a se adaptar à nova realidade, modicando as concepções de gestão dos recursos humanos, voltando-se mais para a área comportamental, a fim de melhorar a comunicação com os colaboradores e entender os seus problemas pessoais (TACHIZAWA; FERREIRA; FORTUNA, 2006). À vista disso, habilidades e competências dos indivíduos passaram a ter maior importância nas organizações, fazendo com que processos como a terceirização, os avanços tecnológicos e de automação e as novas formas de gestão provocassem mudanças expressivas nas práticas de gestão de pessoas (RIBEIRO et al., 2015).

Para Ribeiro et al. (2015), a alta rotatividade e a falta de motivação e de comprometimento pode ser causada por práticas ineficazes de gestão de pessoas, influenciando no desempenho e no desenvolvimento da carreira dos funcionários. Nesse sentido, as organizações têm buscado continuamente o aperfeiçoamento das práticas de gestão de pessoas, a fim de melhorar o desempenho dos colaboradores como os processos de integração e de comunicação, programas de reconhecimento, treinamento e de incentivo (RIBEIRO et al., 2015).

De acordo com Araújo e Garcia (2014), o gestor de pessoas deve ter conhecimento das tecnologias de gestão organizacional que vem surgindo com frequência nos novos momentos dos estudos organizacionais. A evolução da área de gestão de pessoas passou a representar uma solução para o alcance da excelência organizacional, em uma nova era, em que algumas verdades antigas da administração passaram a ser desfeitas com a explosão da informação. Surgiram, assim, novos métodos de seleção, novas avaliações de desempenho e novos benefícios, assim como outros elementos comportamentais, envolvendo poder, liderança e cultura organizacional (ARAÚJO; GARCIA, 2014).

Na visão de Mósca, Cereja e Bastos (2014), há um conjunto de processos de gestão de pessoas nas cadeias de valor em todas as organizações, elencados como básicos e que incluem as obrigações legais. Os processos elencados pelos autores Tais processos são: admissão, envolvendo a seleção, a contratação e a integração; a rescisão do contrato de trabalho; a gestão de férias do pessoal; a folha de pagamentos; o pagamento de autônomos; a gestão de relações de trabalho; a comunicação organizacional; a saúde e a segurança no trabalho; a administração de remunerações, compreendendo os cargos e salários, além dos benefícios e da carreira; o treinamento e desenvolvimento e a avaliação do desempenho dos colaboradores (MÓSCA; CEREJA; BASTOS, 2014).

Além disso, a perspectiva de carreira passou a ser estabelecida em avaliações individuais e coletivas, relacionadas com os objetivos estratégicos da organização, envolvendo líderes motivados e motivadores que utilizem a ferramenta da remuneração para estimular o desempenho, visto que, sem isso, não é possível ter um ambiente de trabalho que se tenha qualidade de vida dos indivíduos (MÓSCA; CEREJA; BASTOS, 2014). Nessa linha de entendimento, Demo, Fogaça e Costa (2018)

realizaram uma pesquisa a fim de identificar a produção acadêmica nacional a respeito de políticas e práticas de gestão de pessoas. 
Dentre os resultados encontrados nos estudos de Demo, Fogaça e Costa (2018) estão: as políticas de envolvimento devem receber maior atenção dos pesquisadores e tiveram como foco a prática de comunicação; os estudos acerca da política de recrutamento e seleção se basearam em indicações em processos seletivos e na adoção de redes sociais; pesquisas quanto à política de remuneração e recompensas apresentaram que o objetivo não é somente o financeiro e sim a percepção de recompensa pelos grupos nas organizações, assim como as relações destas com os valores e a justiça organizacional.

Ademais, houve uma variação também a respeito das pesquisas em relação à política de condições de trabalho, abrangendo várias práticas, como a saúde e a segurança e os estudos voltados à política de avaliação de desempenho por competências, ressaltando seus resultados para a gestão estratégica (DEMO; FOGAÇA; COSTA, 2018).

Desta forma, Rossés et al. (2019) afirmam que a gestão de pessoas qualifica o capital humano das organizações para enfrentar os fatores ambientais. Na perspectiva destes autores, a qualidade dos colaboradores, proporciona uma equipe coesa e integrada, que trabalha em um ambiente de qualidade alcançando os resultados desejados.

A partir desta exposição delimita-se o domínio conceitual e parte-se para a apresentação, na seção seguinte, dos aspectos metodológicos do estudo, que descreve a caracterização deste estudo, bem como os passos que foram empreendidos para coleta e análise dos resultados.

\section{Método do Estudo}

No intuito de atender ao objetivo de identificar as principais práticas de gestão de pessoas adotadas pelas melhores cooperativas para trabalhar, segundo um ranking da Revista Você S/A de 2017, realizou-se um estudo com abordagem qualitativa e quantitativa, caráter descritivo, por meio de dados secundários. A pesquisa quantitativa proporciona mensurar variáveis pré-determinadas, averiguando os dados e generalizando resultados (CHIZZOTI, 2003). Enquanto que a pesquisa qualitativa, para Yin (2016), permite maior liberdade ao pesquisador, além de proporcionar a realização de um estudo aprofundado, abrangendo questões contextuais, que muitas vezes acabam sendo deixados de lado na pesquisa quantitativa.

Em relação à estratégia de pesquisa, o trabalho configura-se como uma pesquisa documental, através da consulta do "Guia Você S/A - As 150 Melhores Empresas para você Trabalhar" edição de 2017, além de acesso aos sites e aos relatórios de sustentabilidade e gestão do ano de 2017 das cooperativas premiadas. Na visão de Richardson (2017), a análise documental fundamenta-se em variadas operações com o propósito de pesquisar e analisar um ou diversos documentos, a fim de identificar as 'podem estar envolvidas.

Quanto à análise dos dados, utilizou-se análise qualitativa e quantitativa à luz do referencial teórico abordado no presente estudo. Além disso, foi adotada a estatística descritiva de frequência para a apresentação e discussão dos resultados. A Revista Você S/A anualmente divulga uma edição das 150 melhores empresas para trabalhar, classificadas em diversas áreas a partir do índice de felicidade no trabalho. Tal análise pode ser justificada pelo fato de a Revista Você S/A ser utilizada por diversos autores em pesquisas científicas, como Silva, Costa e Lemos (2015) e Rocha e Novaes (2018). Assim, no presente estudo foram analisadas, apenas as cooperativas, elencadas pela Revista Você S/A, como as melhores cooperativas para trabalhar em 2017: Sicredi, Sicoob Credicitrus, Sicoob São Miguel, Uniprime Norte do Paraná e nas seguintes cooperativas de saúde premiadas: Unimed Sul Capixaba, Unimed Central de Serviços do Rio Grande do Sul, Unimed Vale do Taquari e Rio Pardo, Unimed São José do Rio Preto, Unimed Porto Alegre, Hospital Unimed Sul Capixaba, Unimed Sorocaba, Unimed Volta Redonda, Central Nacional Unimed, Unimed Missões Rio Grande do Sul, Hospital Dr. Miguel Soeiro, Unimed Chapecó (REVISTA VOCÊ S/A, 2017). 
A seguir a Figura 1 demonstra as categorias analíticas utilizadas para desenvolver este estudo, optou-se por segmentá-las em: caracterização das cooperativas e práticas de gestão de pessoas.

Figura 1 - Categorias Analíticas

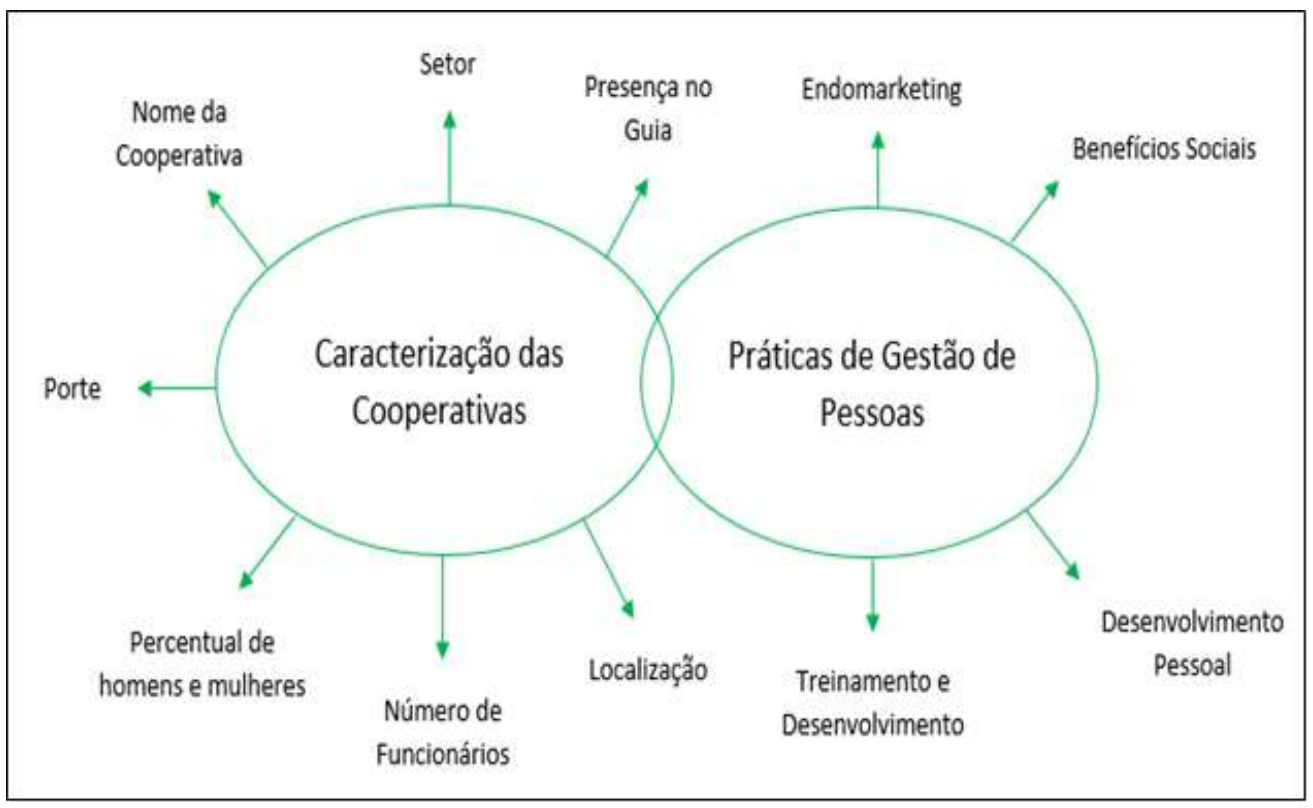

Fonte: Elaborado pelos autores, com base em Campos et al. (2015).

A partir da Figura 1 nota-se que a caracterização das cooperativas será feita de acordo com, Periodicidade no Guia Melhores Empresas para Trabalhar, setor de atuação da cooperativa, índice de Felicidade no Trabalho, porte da cooperativa, número de funcionários, percentual de homens e mulheres e localização. Já as práticas de Gestão de Pessoas serão apresentadas, por meio de quatro categorias: Endomarketing, Desenvolvimento Pessoal, Treinamento e Desenvolvimento e Benefícios Sociais.

A seguir são apresentados os resultados obtidos a partir da análise das categorias analíticas.

\section{Análise e Discussão dos Resultados}

Nessa seção serão apresentadas as análises e discussões dos resultados do presente estudo. Essa seção subdivide-se em: perfil das cooperativas analisadas, práticas de gestão de pessoas em cooperativas de crédito e de saúde e pontos a melhorar nas cooperativas analisadas.

\subsection{Perfil das cooperativas analisadas}

A partir da análise das 150 melhores empresas brasileiras para trabalhar, realizada pela Revista Você S/A da edição de 2017, chegou-se ao total de 16 cooperativas, distribuídas em dois ramos de atuação (crédito e saúde) sendo estas, objeto de análise do presente estudo.

Em relação à periodicidade, no Guia das Melhores Empresas para Trabalhar, promovido pela Você S/A, nota-se que grande parte das cooperativas (31,25\%) já apareceu entre um a dois anos no ranking, o que representa que esse tipo societário vem crescendo e se profissionalizando cada vez mais no país. Além disso, destacam-se 4 cooperativas que se fazem presentes há mais de dez anos no guia, em ordem decrescente quanto à frequência, são elas: Unimed Vale do Taquari e Rio Pardo, Unimed Missões Rio Grande do Sul, Central Nacional Unimed e Sicredi (VOCÊ S/A, 2017). Esse cenário indica a dedicação ao aperfeiçoamento constante na gestão destas organizações, seja pelo 
trabalho do conselho de administração quanto do engajamento dos associados e colaboradores em se fazerem presentes e participativos nas assembleias.

No que tange ao ramo de atuação, no Brasil, as cooperativas estão classificadas em 13 ramos de atividades econômicas, são elas, agropecuário, consumo, crédito, educacional, especial, habitacional, infraestrutura, mineral, produção, saúde, trabalho, transporte, turismo e lazer (GUARDABASSIO; AMORIM; PEREIRA, 2013) suas diferenças estão pautadas pela atividade econômica que desenvolvem (FREITAS; FREITAS, 2013). Entretanto, as que obtiveram destaque entre as Melhores Empresas para Trabalhar, a maioria pertence ao setor de saúde (75\%), desenvolvendo suas atividades principalmente nos estados de São Paulo e Rio Grande do Sul (ambos com 31,25\%), e o restante pertence ao setor de crédito (25\%).

Em relação ao número de funcionários, constatou-se que todas as empresas possuem mais de 200 colaboradores, predominando organizações entre 200 a 1000 funcionários $(68,75 \%)$. Esses dados sugerem que as empresas de maior porte como as de médio e grande possuem práticas de gestão de pessoas mais formalizadas e disseminadas publicamente.

Quanto ao percentual de homens e mulheres, constatou-se que há maior incidência de mulheres $(93,75 \%)$ na totalidade das cooperativas pesquisadas. Ressalta-se que em apenas em uma das cooperativas houve um maior percentual de homens. De acordo com a Revista VOCÊ S/A, no setor de saúde, o número de mulheres chega a $73 \%$, sendo muito mais representativo do que nas cooperativas de crédito (54\%). Fato esse que pode ser observado até mesmo por uma questão histórico-cultural, no qual o gênero feminino é predominante nas profissões relacionadas a área da saúde e da educação (FERNANDES; CARDIM, 2018).

O Índice de Felicidade no Trabalho (IFT) utilizado pela Você S/A é uma adaptação do indicador de Felicidade Interna Bruta (FIB) da Organização das Nações Unidas. A sua finalidade é mensurar o crescimento de um país sem considerar apenas o aspecto econômico, mas levando em consideração conceitos culturais, psicológicos, espirituais e ambientais do mesmo. Com isso, percebe-se que cinco cooperativas das 16 cooperativas analisadas, obtiveram nota igual ou superior a 81, destas quatro são do setor de saúde e uma de crédito, são elas: Unimed Sul Capixaba, Unimed Central de Serviços do Rio Grande do Sul, Unimed Vale do Taquari e Rio Pardo, Unimed São José do Rio Preto e Sicredi, respectivamente (VOCÊ S/A, 2017). 
A Tabela 1 apresenta uma síntese do perfil das organizações o perfil destas organizações.

Tabela 1 - Perfil das cooperativas analisadas

\begin{tabular}{|c|c|c|c|}
\hline Categorias & Variáveis & $\begin{array}{|ll|}\text { No } & \text { de } \\
\text { Empresas } & \\
\end{array}$ & Percentual \\
\hline $\begin{array}{l}\text { Periodicidade no Guia Melhores } \\
\text { Empresas para Trabalhar }\end{array}$ & $\begin{array}{|cccc|}1 & - & 2 & \text { anos } \\
3 & - & 4 & \text { anos } \\
5 & - & 6 & \text { anos } \\
7 & - & 8 & \text { anos } \\
9 & - & 10 & \text { anos } \\
11 & - & 12 & \text { anos } \\
13-14 \text { anos } & & \\
\end{array}$ & $\begin{array}{l}5 \\
2 \\
1 \\
2 \\
2 \\
3 \\
1 \\
\end{array}$ & \begin{tabular}{|l|}
$31,25 \%$ \\
$12,50 \%$ \\
$6,25 \%$ \\
$12,50 \%$ \\
$12,50 \%$ \\
$18,75 \%$ \\
$6,25 \%$ \\
\end{tabular} \\
\hline $\begin{array}{l}\text { Nota Final (Índice de Felicidade } \\
\text { no Trabalho) }\end{array}$ & $\begin{array}{|lll|}73 & - & 75 \\
75 & - & 77 \\
78 & - & 80 \\
81-83 & & \\
\end{array}$ & $\begin{array}{l}6 \\
1 \\
4 \\
5\end{array}$ & $\begin{array}{l}37,50 \% \\
6,25 \% \\
25 \% \\
31,25 \%\end{array}$ \\
\hline Setor & \begin{tabular}{|l|} 
Crédito \\
Saúde
\end{tabular} & $\begin{array}{l}4 \\
12 \\
\end{array}$ & $\begin{array}{l}25 \% \\
75 \%\end{array}$ \\
\hline Porte & $\begin{array}{l}\text { Pequeno } \\
\text { Médio } \\
\text { Grande }\end{array}$ & $\begin{array}{l}2 \\
7 \\
7\end{array}$ & $\begin{array}{l}12,50 \% \\
43,75 \% \\
43,75 \%\end{array}$ \\
\hline Número de Funcionários & \begin{tabular}{|lrrr}
200 & a & 1000 & funcionários \\
1001 & a & 2000 & funcionários \\
Mais & de & 15000 \\
funcionários &
\end{tabular} & $\begin{array}{l}11 \\
4 \\
1\end{array}$ & $\begin{array}{l}68,75 \% \\
25 \% \\
6,25 \%\end{array}$ \\
\hline $\begin{array}{l}\text { Comparação entre homens e } \\
\text { mulheres }\end{array}$ & $\begin{array}{|ll|}\text { Maior percentual } & \text { de } \\
\text { homens } & \\
\text { Maior percentual de } \\
\text { mulheres }\end{array}$ & $\begin{array}{l}1 \\
15\end{array}$ & $\begin{array}{l}6,25 \% \\
93,75 \%\end{array}$ \\
\hline Estado & $\begin{array}{|lrr|}\text { Espírito } & & \text { Santo } \\
\text { Paraná } & & \\
\text { Rio de de } & \text { Janeiro } \\
\text { Rio Grande } & \text { do Sul } \\
\text { Santa } & \text { Catarina } \\
\text { São Paulo } & \\
\end{array}$ & $\begin{array}{l}2 \\
1 \\
1 \\
5 \\
2 \\
5\end{array}$ & \begin{tabular}{l|}
$12,50 \%$ \\
$6,25 \%$ \\
$6,25 \%$ \\
$31,25 \%$ \\
$12,50 \%$ \\
$31,25 \%$
\end{tabular} \\
\hline
\end{tabular}

Fonte: Elaborado pelos autores, com base nos dados do Guia Você S/A - As 150 Melhores Empresas para você trabalhar (2017).

A seguir são apresentados os resultados obtidos a partir da análise das principais ações desenvolvidas pelas cooperativas de crédito e de saúde até o período analisado.

\subsection{Práticas de Gestão de Pessoas em Cooperativas de Crédito e de Saúde}

Visando analisar as práticas de gestão de pessoas praticadas pelas melhores cooperativas de crédito e de saúde para trabalhar no Brasil, segundo o guia da Você S/A de 2017, na Figura 2 foram destacadas as principais ações desenvolvidas pelas organizações até o período analisado. 
Figura 2 - Práticas de Gestão de Pessoas praticadas pelas Cooperativas de Crédito e de Saúde

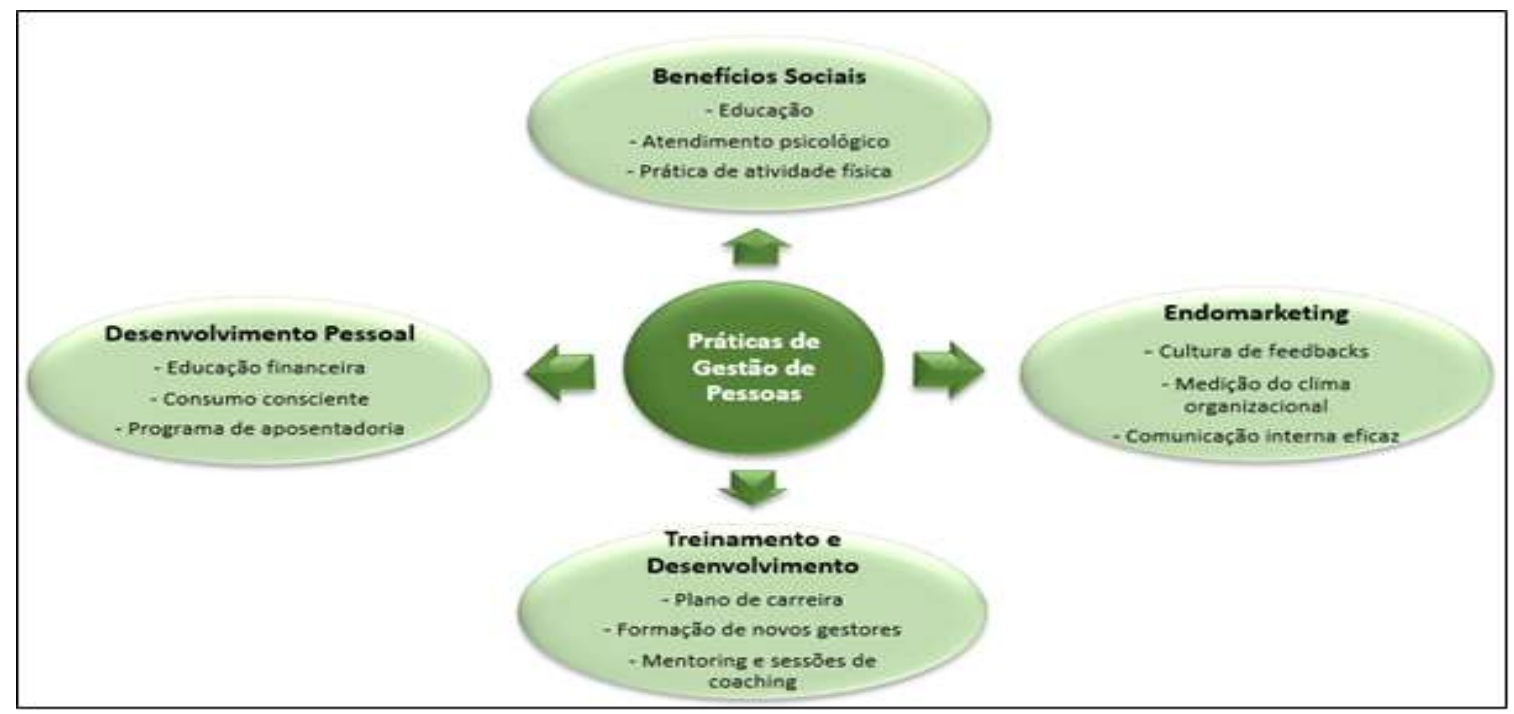

Fonte: Elaborado pelos autores, com base nos dados dos do Guia Você S/A - As 150 Melhores Empresas para você trabalhar (2017).

As principais ações desenvolvidas pelas cooperativas de crédito e de saúde, foram subdivididas em quatro categorias analíticas: Endomarketing, Desenvolvimento Pessoal, Treinamento e Desenvolvimento e Benefícios Sociais.

Em relação a categoria analítica "Endomarketing" e suas respectivas ações para a manutenção de um bom clima organizacional juntamente com práticas de comunicação interna (BEKIN, 2004), é possível constatar a presença desta prática de forma totalitária nas cooperativas de crédito ao contrário do setor de saúde, em que apenas metade delas utiliza está prática. Isso reflete no constructo qualidade de vida no trabalho, que obteve resultados benéficos tanto em cooperativas de saúde quanto nas de crédito.

Na visão de Almeida et al. (2017), os indivíduos buscam incessantemente por uma melhoria na qualidade de vida para satisfação profissional ou pessoal. Além disso, outros fatores como as tecnologias, o ritmo de vida veloz, a pressão por resultados e a estrutura de trabalho atingem de modo direto as pessoas na atualidade (ALMEIDA et al., 2017).

Assim, pode-se inferir que esse cenário está alinhado, visto que Carnevalli e Tófani (2008) afirmam que o endomarketing realmente será praticado quando os funcionários são considerados o primeiro mercado interno para as empresas e que estas devem alinhar a imagem que transmitem ao mercado com a que o seu público interno visualiza. Nesse sentido, os colaboradores passam a ser vistos como aliados ao sucesso do negócio e não como mera força de trabalho remunerado. Alguns exemplos de ações de endomarketing seriam ações realizadas para ouvir constantemente a opinião do colaborador, medição do clima organizacional, realização de feedbacks para melhoria contínua da equipe e do espaço de trabalho e também meios para evitar ao máximo, ruídos que poderão atrapalhar a eficácia da comunicação interna.

Em relação às ações de desenvolvimento pessoal, promovidas pelas cooperativas de crédito e de saúde, estas auxiliam o colaborador na sua vida fora do ambiente laboral, nota-se que essas ações tiveram a mesma importância para ambos ramos de cooperativas estudados, contando com algumas ações voltadas ao tripé da sustentabilidade, ou seja, a questões ambientais, sociais e econômicas (ELKINGTON, 1997). Como principais ações de desenvolvimento pessoal, tem-se a reeducação de consumo, uso consciente dos recursos naturais, reciclagem, educação financeira, oficinas de voluntariado, programa de aposentadoria a fim preparar o colaborador e auxiliar a planejar sua vida 
financeira após o seu desligamento da empresa, entre outras. Para Carvalho e Silva (2017), cabe a área de Gestão de Pessoas oferecer o suporte necessário para que os indivíduos aprimorem suas competências em nível organizacional e pessoal.

No que tange às ações de treinamento e desenvolvimento (T\&D), nota-se que estas apareceram de forma muito mais frequente, nas cooperativas de crédito e de saúde, relatando a preocupação destas organizações em realizar práticas que promovam melhorias no desempenho de seus membros. Investir no desenvolvimento das pessoas que realizam o trabalham nas organizações é investir na qualidade dos produtos e serviços e, consequentemente, atender melhor os clientes, estimulando assim o aumento das vendas (TACHIZAWA et al., 2006). Isso é refletido na preocupação de algumas empresas em realizar programas de mentoring, sessões de coaching, treinamentos e capacitações a fim de preparar os profissionais a crescerem dentro da cooperativa, alinhando o processo de formação de novos gestores com o plano de carreira oferecido pelas mesmas. Ressalta-se que segundo Demo, Fogaça e Costa (2018), a prática de TD\&E é a mais privilegiada no que tange a pesquisas científicas.

Por fim, a respeito dos benefícios sociais relacionados a educação, lazer e bem-estar praticados aos colaboradores das cooperativas de crédito e de saúde, foi identificado que a metade das cooperativas de crédito os concede diferentemente das do ramo de saúde. Têm-se como exemplos de ações, o atendimento psicológico para tratar problemas comuns no dia a dia como ansiedade, estresse, depressão e Síndrome de Burnuot; clube fit (relacionado a práticas de combate ao sedentarismo e lesões relacionadas a falta de atividade física) e também recursos destinados a inserir o colaborador no meio acadêmico, possibilitando com que o mesmo obtenha um curso superior, uma especialização e até mesmo, uma pós-graduação e, consequentemente, cresça na organização e tenha um aumento salarial.

Segundo Goulart et al. (2018), as organizações preocupam-se em adquirir o melhor desempenho de seus colaboradores, constantemente, bem como responsabilidade e comprometimento deles com os resultados. Com isso, passa ser necessário revisar os aspectos remuneratórios e a definição de prêmios por desempenho, meritocracia ou remuneração variável. Por intermédio desses fomentos, a organização busca elevar a produtividade e um melhor desempenho, no sentido em que se entende que a entrega é proporcional ao ganho, no contexto empresarial (GOULART et al., 2018).

A partir das análises das ações de Endomarketing, Desenvolvimento Pessoal, Treinamento e Desenvolvimento e Benefícios Sociais, coletados através da consulta do "Guia Você S/A - As 150 Melhores Empresas para você Trabalhar" edição de 2017, além de acesso aos sites e aos relatórios de sustentabilidade e gestão do ano de 2017 das cooperativas premiadas, a seguir são apresentados os pontos a melhorar detectados nas cooperativas de crédito e saúde estudadas.

\subsection{Pontos a melhorar nas cooperativas analisadas}

$\mathrm{Na}$ intenção de abordar de maneira mais específica a situação da área de gestão de pessoas das cooperativas observadas, utilizou-se a análise da Revista Você S/A, na qual aponta as práticas de gestão de pessoas que podem ser aperfeiçoadas pelas cooperativas. Com isso, o Tabela 2 relata as oportunidades de melhoria nas cooperativas de crédito. 
Tabela 2 - Pontos a melhorar nas cooperativas de crédito

\begin{tabular}{l|l}
\hline $\begin{array}{l}\text { Pontos a melhorar nas cooperativas de } \\
\text { crédito }\end{array}$ & Frequência no Guia \\
\hline $\begin{array}{l}\text { Dificuldades de comunicação entre matriz e } \\
\text { filiais }\end{array}$ & 2 \\
\hline Melhoria no processo de feedbacks & 2 \\
\hline Plano de carreira melhor estruturado/aplicado & 2 \\
\hline Implantação do Job Rotation & 1 \\
\hline Construção de espaços de lazer & 1 \\
\hline
\end{tabular}

Fonte: Elaborado pelos autores, com base nos dados dos do Guia Você S/A - As 150 Melhores Empresas para você trabalhar (2017).

A dualidade das cooperativas de créditos encontra-se na busca por resultados que atendam às necessidades dos seus associados, ao mesmo tempo, que priorizam a sustentabilidade no mercado complexo, dinâmico e de mudanças rápidas, buscando a eficiência financeira, produtiva e social (BEGNINI; ORO, 2018). Em seu estudo, estes autores perceberam que os gestores das cooperativas de crédito estão mais preocupados em atender as necessidades de sua equipe e dos associados do que com o desempenho econômico-financeiro, sendo esse um consequente de uma relação de trabalho satisfatória.

Entretanto, como pode ser observado na Tabela 2, algumas práticas de gestão de pessoas ainda merecem atenção no ramo de crédito, são elas: as dificuldades de comunicação entre matriz e filiais, que podem afetar a sinergia das agências; a melhoria no processo de feedbacks, a fim de que houvesse maior frequência de encontros para ser abordado tal atividade, e assim, os colaboradores fossem orientados de forma mais eficaz de como aumentar seu desempenho dentro da organização; e, atualização do plano de carreira já existente e maior difusão do mesmo, por parte da direção, possibilitando que haja ascensões de profissionais.

Em relação às oportunidades de melhoria nas cooperativas de saúde, nota-se na Tabela 3 que as questões que emergiram com maior frequência no Guia foram os referentes ao Planos de Cargos, Salários e Carreiras.

Percebe-se que o plano de carreira é uma ferramenta capaz de promover atração e retenção de talentos pelo fato do colaborador poder visualizar um caminho a ser traçado, proporcionando sanar suas necessidades básicas intrínsecas e extrínsecas, como salário, segurança no cargo, reconhecimento, autoconfiança, entre outros fatores ligados diretamente a motivação dos mesmos (SCHUSTER; DIAS, 2012). Por isso, merece maior destaque, podendo contar com soluções para torná-lo mais claro e de fácil compreensão pela equipe de trabalho, pois muitos almejam candidatarem-se para vagas de recrutamento interno e necessitam de algum suporte como a descrição de competências para cada vaga, experiências, entre outros fatores que deveriam estar apresentados no plano.

Outro elemento importante de ser ressaltado, com relação as carreiras nas cooperativas de saúde, seria a implementação de um sistema de carreira em Y, visando assim, possibilitar maior autonomia ao colaborador de qual caminho deseja seguir dentro da organização. 
Tabela 3 - Pontos a melhorar nas cooperativas de saúde

\begin{tabular}{l|l}
\hline Pontos a melhorar nas cooperativas de saúde & Frequência no Guia \\
\hline Plano de carreira estruturado & 7 \\
\hline $\begin{array}{l}\text { Práticas robustas sobre diversidade no ambiente } \\
\text { laboral }\end{array}$ & 3 \\
\hline Planejamento de aposentadoria & 2 \\
\hline Dificuldade dos gestores à mudança & 2 \\
\hline $\begin{array}{l}\text { Funcionários mal acomodados devido a pequena } \\
\text { estrutura }\end{array}$ & 1 \\
\hline Participação nos lucros & 1 \\
\hline Maior autonomia das áreas & 1 \\
\hline Comunicação interna & 1 \\
\hline Necessidade de gestão do conhecimento & 1 \\
\hline
\end{tabular}

Fonte: Elaborado pelos autores, com base nos dados dos do Guia Você S/A - As 150 Melhores Empresas para você trabalhar (2017).

Além disso, outra ação que ainda pode ser explorada pelas cooperativas de saúde, refere-se à implantação de práticas mais concretas envolvendo questões de diversidade. Seja de etnia, gênero ou sexualidade como, por exemplo, a extensão dos homens ao auxílio-creche ou babá (hoje restrito apenas às funcionárias mulheres). Outrossim, as cooperativas de saúde também proporcionar mais discussões acerca desse assunto, minimizando o conservadorismo existente em algumas instituições cooperativas. Assim, para reduzir a dificuldade dos gestores à mudança, questões de trabalho já existentes devem ser reformuladas como a política de horário flexível e a maior participação dos funcionários nas formulações das estratégias.

Outro ponto a ser destacado seria o planejamento de aposentadoria aos colaboradores a fim de melhor prepará-los para a fase de desligamento da cooperativa e para a futura experiência fora do ambiente de trabalho. Nesse sentido, o colaborador recém-aposentado pode, por exemplo, ocupar melhor o seu tempo, atuando nas ações sociais praticadas e apoiadas pela própria organização.

\section{Conclusões}

No presente estudo procurou-se identificar as principais práticas de gestão de pessoas adotadas pelas melhores cooperativas para trabalhar, segundo um ranking da Revista Você S/A do ano de 2017. As cooperativas analisadas pertencem a dois ramos, crédito e saúde, totalizando 16, sendo 12 de saúde e o restante de crédito.

Tal objetivo foi alcançado por meio dos resultados obtidos, sendo possível observar que, na presente pesquisa, a maioria das cooperativas estudadas pertence ao ramo da saúde. Além disso, existe um predomínio das cooperativas analisadas nas regiões sul e sudeste do Brasil, e também são caracterizadas em sua maioria como de médio e grande porte. Quanto ao quadro de colaboradores, grande parte delas é composta por 200 a 1.000 pessoas, sendo este predominantemente do gênero feminino.

As análises das práticas de gestão de pessoas praticadas pelas cooperativas de crédito e saúde foram classificadas nas seguintes categorias analíticas: Endomarketing, Desenvolvimento Pessoal, Treinamento e Desenvolvimento (T\&D) e Benefícios Sociais. 
No ramo de crédito, nota-se que a prática de gestão de pessoas que possui maior expressividade é o endomarketing seguido pelas práticas de T\&D. Já no ramo da saúde, as práticas de gestão de pessoas mais significativas referem-se aos benefícios sociais ao T\&D. Ressalta-se nas cooperativas de saúde existem também uma ampla preocupação com a qualidade de vida no trabalho.

Sobre o índice de felicidade no trabalho calculado pela Você S/A, constatou-se que cinco cooperativas obtiveram nota igual ou superior a 81, destas quatro são do ramo de saúde e uma de crédito.

No que tange aos pontos que possuem oportunidades de melhoria nas práticas de gestão de pessoas, ao realizar um paralelo observa-se que nas cooperativas de saúde foram apontados mais aspectos a serem adotados ou reformulados do que no ramo de crédito. Sendo assim, nas cooperativas de crédito as maiores necessidades de aprimoramento seriam: comunicação entre matriz e filiais, refinamento do processo de feedback e no plano de carreira (reestruturando-o nas cooperativas que já o tem). Já nas cooperativas de saúde, os aspectos de implantação e/ou mudanças necessárias seriam: plano de carreira estruturado, práticas robustas sobre diversidade no ambiente laboral, planejamento de aposentadoria e ações para minimizar a dificuldade existente dos gestores à mudança.

Assim, vale destacar que em ambas o plano de carreira se faz muito presente, ou seja, reflete a demanda dos colaboradores em ascenderem dentro da empresa, motivando-os em busca de maior competência técnica (instrução, conhecimento, experiência e habilidades) e propiciando que o funcionário atinja seus objetivos individuais juntamente com os organizacionais.

Segundo Araújo et al. (2007), um dos grandes desafios das organizações cooperativas está em adaptar-se às regras impostas pelo mercado e desafios para manter-se fiéis aos seus princípios em ambientes competitivos, entretanto estas organizações ajustam-se e continuam atuando, garantindo assim sua competitividade.

A construção dessa pesquisa justifica-se tanto teoricamente quanto na questão prática, no sentido em que elabora uma linha de entendimento que vai ao encontro do que diz a literatura e traz contribuições sobre metodologias e práticas da área de gestão de pessoas que já estão sendo implementadas ou podem ser implementadas para auxiliar na gestão das organizações cooperativas. A partir deste estudo, nota-se que o tema não se esgota, permitindo que novos trabalhos sejam desenvolvidos a fim de identificar com maior profundidade as temáticas em questão com o intuito de complementar, comparar e confirmar resultados obtidos neste trabalho.

Ressalta-se ainda que, esta pesquisa possui como limitações o fato de valer-se apenas de levantamentos dos guias e sites analisados. Desta forma, sugere-se a realização de novas pesquisas visando o aprofundamento da análise, que poderia ser desenvolvida por meio de um contato direto com as organizações envolvidas, por meio de visitas, observações e entrevistas com gestores e colaboradores de cooperativas. Por fim, este estudo é limitado aos locais pesquisados, o que impossibilita a generalização dos resultados a outros campos. Como sugestão para trabalhos futuros, orienta-se a aplicação desta metodologia de análise das práticas de gestão de pessoas em outras organizações cooperativas a fim de traçar um paralelo e obter um panorama geral das práticas de gestão de pessoas desenvolvidas por organizações cooperativas.

\section{Referências}

ALMEIDA, A. R. de. A Cooperativa como espaço organizacional: um estudo das características de gestão de pessoas em cooperativas de crédito. 96 f. Dissertação (Mestrado em Administração). Curso de Pós-Graduação em Administração, Universidade Federal de Santa Catarina: Florianópolis, 2008. 
ALMEIDA, D. M.; TOMAZZONI, G. C.; SANTOS, A. S.; RODRIGUES, G. O.; SIMONETTO, E. O. Análise de cenários envolvendo satisfação no trabalho e estresse ocupacional por meio da dinâmica de sistemas. Future Studies Research Journal. v. 9, n. 1, p. 78-94, jan/abr. 2017.

ARAUJO, Z. A. S.; SIQUEIRA, E. S.; BINOTTO, E.; SIMIONI, F. J. Complementariedade entre governança corporativa e cooperativismo: Os deslocamentos entre a dimensão estratégica e a cotidiana. Encontro Nacional de Pós-Graduação em Administração - EnANPAD, Rio de Janeiro. Anais... 2007.

ARAÚJO, L. C. G.; GARCIA, A. A. Gestão de pessoas: Estratégias e integração organizacional. 2ed. São Paulo: Atlas, 2014.

BEGNINI, S.; ORO, I. M. Relação entre eficiência financeira-operacional e o tamanho das cooperativas de crédito de Santa Catarina. Encontro Nacional de Pós-Graduação em Administração EnANPAD, Curitiba. Anais... 2018.

BEKIN, S. F. Endomarketing: como praticá-lo com sucesso. São Paulo: Pentrice Hall, 2004.

CAMPOS, S. A. P.; ANDRADE, T.; ESTIVALETE, V. F. B.; COSTA, V. F.; STEFANAN, A. A. Práticas de responsabilidade social corporativa e gestão de pessoas no contexto brasileiro: uma análise das Empresas Modelo em sustentabilidade e melhores para trabalhar. REA - Revista de Administração da UFSM, Santa Maria, v. 8, n. 2, p. 184-201, abr/jun. 2015.

CARVALHO, A. D.; PERES, J. M. O papel da gestão de pessoas em cooperativas agropecuárias como desenvolvimento regional. Revista FATEC Sebrae em debate: gestão, tecnologias e negócios. v. 2, n. 3, p. 37-52, 2015 .

CARVAlHO, A. D.; SILVA, B. A. R. A gestão de pessoas e o relacionamento interpessoal no cooperativismo. Recape - Revista de Carreiras e Pessoas, v. 7, n. 3, p. 139-150, 2017.

CARNEVALLI, V. M. L; TÓFANI, F. Endomarketing como ferramenta estratégica de valorização do cliente interno. Disponível em: www.webartigos.com/artigos/endomarketingcomo-ferramenta-de-valorização-do-cliente-interno/7484/. Acesso em: 14 set. 2018.

CHARTERINA, A. M. Las cooperativas y su acción sobre la sociedad. Revesco Monográfico: Las sociedades cooperativas construyen um mundo mejor, n. 117, p.34- 49, 2014.

CHIZZOTTI, A. Pesquisa em ciências humanas e sociais. 6. ed. São Paulo: Cortez, 2003.

COMUNELLO, F.; SANDRIN, L.; BIZUS, M. C.; BOCK, S.; TOSTA, H. T. Análise dos princípios cooperativistas na gestão de uma cooperativa de crédito. CONVIBRA 2014 - III Congresso Online Gestão, Educação e Promoção da Saúde. Disponível em: www.convibra.com.br/upload/paper/2014/39/2014_39_10282.pdf. Acesso em: 15 jun. 2019. Anais... 2014 .

COSTA, A. C.; DEMO, G.; PASCHOAL, T. Políticas e práticas de gestão de pessoas produzem servidores públicos resilientes? Evidência da validação de um modelo estrutural e de modelos de mensuração. Revista Brasileira de Gestão de Negócios, v. 21, n. 1, p. 70-85, 2019.

DELFINO, I. A. L., LAND, A. G. RUFINO, W. A relação entre valores pessoais e organizacionais em uma cooperativa comparados com os princípios do cooperativismo. Encontro Nacional de PósGraduação em Administração - EnANPAD, Rio de Janeiro. Anais... 2010. 
DEMO, G. Políticas de gestão de pessoas nas organizações: papel dos valores pessoais e da justiça organizacional. zed. São Paulo: Atlas, 2010.

DEMO, G.; FOGAÇA, N.; COSTA, A. C. Políticas e práticas de gestão de pessoas nas organizações: Cenário da produção nacional de primeira linha e agenda de pesquisa. Cadernos EBAPE.BR, v. 16, n. 2, p. 251-263, 2018.

DUARTE, C. A. S.; JESUS-LOPES, J. C. J.; SANTOS, L . Cooperativas: Um levantamento bibliométrico da produção científica do ENANPAD entre 2010-2014. Desafio Online, v. 4, n. 1, p. 117-134, 2016.

DUTRA, J. S. Gestão de pessas: Modelo, processos, tendências e perspectivas. 1ed. São Paulo: Atlas, 2009.

ELKINGTON, J. Cannibals with forks: Triple bottom line of 21st century business. 1ed. Oxford: Capstone, 1997.

FERNANDES, I. M. B.; CARDIM, S. Percepção de futuros docentes portugueses acerca da subrepresentação feminina nas áreas e carreiras científico-tecnológicas. Educação e Pesquisa. v. 4, 2018.

FLAVIANO, V. Satisfação e comprometimento organizacional em cooperativas agrícolas. Dissertação (Mestrado em Administração) - Programa de Pós-graduação em Administração. Santa Maria: UFSM, 2014.

FREITAS, F. F. FREITAS, A. F. O cooperativismo de crédito no Brasil e a emergência de uma vertente solidária. Encontro Nacional de Pós-Graduação em Administração - EnANPAD, Rio de Janeiro. Anais... 2013.

GOULART, E. L.; RODRIGUES, C. S.; MOREIRA, V. R.; WEYMER, A. S. Q. A relação entre os indicadores de recursos humanos e o desempenho econômico financeiro das cooperativas agropecuárias Paranaenses. Revista de Gestão e Organizações Cooperativas. v.5, n.9 jan./jun, 2018.

GUARDABASSIO, E. V.; AMORIM, W.; PEREIRA, R. S. Geração de trabalho e renda por meio do cooperativismo. Encontro Nacional de Pós-Graduação em Administração - EnANPAD, Rio de Janeiro. Anais. 2013.

LACOMBE, F. J. M. Recursos humanos: Princípios e tendências. zed. São Paulo: Saraiva, 2011.

MARIANO, T. L. A. B.; MOSCON, D. C. B. As relações entre as práticas de gestão de pessoas e o desenvolvimento de vínculos com a organização: um estudo em uma empresa de contabilidade. Revista Gestão e Planejamento, Salvador, v. 19, p. 227-243, jan./dez. 2018.

MÓSCA, H. M. B.; CEREJA, J. R.; BASTOS, S. A. P. Gestão de pessoas nas organizações contemporâneas. 1ed. Rio de Janeiro: LTC, 2014.

OCB. Organização das Cooperativas Brasileiras. O que é o cooperativismo. 2018. Disponível em: www.ocb.org.br/o-que-e cooperativismo>. Acesso em: 13 set. 2018.

PILETTI, D.; BORGES, G. R.; BARROS, I. C. R. Os princípios do cooperativismo e o trabalho em equipe em cooperativas de Garibaldi-RS. Revista Navus, Florianópolis, v. 5, n. 4, p. 34-45, out./dez. 2015 . 
REVISTA VOCÊ S/A. 15o Melhores empresas para trabalhar, São Paulo: Abril, p. 64-74, out. 2017.

RIBEIRO, I.; CAPPONI, M. B. B.; CARVALHO, A. O.; SERRA, F. A. R. Práticas de gestão de pessoas: Uma análise a partir da percepção de gerentes e não gerentes. Revista de Gestão e Secretariado GeSec. v. 6, n. 1, p. 1-22, Jan/Abr. 2015.

RICHARDSON, R. J. Pesquisa social: Métodos e técnicas. 4.ed. São Paulo: Atlas, 2017.

ROCHA, S. A.; NOVAES, C. A. A problemática do turismo, academia e empregabilidade do profissional no mercado: Um ensaio. Gestión Turística. n. 8, p. 61-74, 2018.

ROSSÉS, G. F.; BOROCHEDES, I. M.; STECCA, J. P. STECCA, F. L. P.; SILVA, A. F. Um estudo sobre os processos de gestão de pessoas em uma cooperativa de crédito. Revista de Gestão e Organizações Cooperativas - RGC, v. 6, n. 11, 2019.

SCHUSTER, M.; DIAS, V. Plano de carreira nos sistemas de gestão público e privado: uma discussão a luz das teorias motivacionais. Revista de Administração Imed. Passo Fundo, v. 2, n. 1, p. 1-17, 2012.

SIMIONI, F. J.; SIQUEIRA, E. S.; BINOTTO, E.; SPERS, E. E.; ARAÚJO, Z. A. S. Lealdade e oportunismo nas cooperativas: desafios e mudanças na gestão. Revista de Economia e Sociologia Rural, v. 47, n. 3, p. 739-76, jul/set, 2009.

SILVA, M. A. C.; COSTA, A. S. M.; LEMOS, A. H. C. A Discriminação certificada: O discurso da Revista Você S/A. sobre a obrigatoriedade da Pós-Graduação para inserção no mercado de trabalho. Revista Pensamento Contemporâneo em Administração. v.9, n.1, p.16-34, jan/mar. 2015.

TACHIZAWA, T.; FERREIRA, V. C. P.; FORTUNA, A. A. M. Gestão com pessoas: uma abordagem aplicada às estratégias de negócios. 5ed. Rio de Janeiro: Editora FGV, 2006.

TARADENKO, P. A influência das dimensões de cultura, liderança e aprendizagem na inovatividade de uma organização cooperativa. $121 \mathrm{f}$. Dissertação (Mestrado em Gestão de Cooperativas). Curso de Pós-Graduação em Gestão de Cooperativas, Pontifícia Universidade Católica do Paraná: Curitiba, 2016.

VEIGA, S. M. FONSECA, I. Cooperativismo: uma evolução pacífica em ação. Rio de Janeiro: DP\&A, 2001.

VERGARA, S. C. Gestão de pessoas. 16ed. São Paulo: Atlas, 2016.

YIN, R. K. Pesquisa qualitativa do início ao fim. Porto Alegre: Penso, 2016.

ZUCATTO, L. C. SILVA, T. N. Cooperativismo de eletrificação rural gaúcho: Um estudo em busca de elementos do empreendedorismo cooperativo. Encontro Nacional de Pós-Graduação em Administração - EnANPAD, São Paulo. Anais... 2017. 